\title{
Therapeutic Hypothermia in Traumatic Brain injury; Review of History, Pathophysiology and Current Studies
}

\author{
Do-Keun Kim, M.D., and Dong-Keun Hyun, M.D., Ph.D.
}

Department of Neurosurgery, Inha University Hospital, Incheon, Korea

The fact that therapeutic hypothermia $(\mathrm{TH})$ has lowered intracranial pressure and protected brain in severe traumatic brain injury (TBI) is well known throughout past sources and experimental data. In this paper, the result of TH in TBI needs to be confirmed. The result of North American Brain Injury Study; Hypothermia (NAVIS-H) 1 and 2, Eurotherm3235, Japan trauma society study was reviewed throughout randomized controlled study which performed recently. The prognosis was not confirmed throughout TH in NAVIS-H1; however, there was statistical significance among the group of 45 years or less and below 35 degree in celcius which checked when he or she visited initially. Hence, NAVIS-H2 study was preceded. In patient who had surgically removed hematoma, the effects of TH were proved compared to diffuse brain damage in NAVIS-H2 study. This was found in the result of Japan neurotrauma data bank. Eurotherm study has been doing, which leads to collect many data later on. The TBI of TH makes them better prognosis in patients who had surgically removed hematoma and lowered initial body temperature. Later on, it is considered further study is necessary.

Key Words: brain injuries; hypothermia.

\section{Introduction}

The definition of therapeutic hypothermia (TH) is controlling lower core body temperature for therapeutic reasons.[1] The hypothermia was classified in 4 categories; mild $\left(32-35^{\circ} \mathrm{C}\right)$, moderate $\left(28-32^{\circ} \mathrm{C}\right)$, severe $\left(20-28^{\circ} \mathrm{C}\right)$, profound $\left(<20^{\circ} \mathrm{C}\right)$. The degree of hypothermia is normally determined by the core temperature measured rectally, in the esophagus, or in the bladder.[2] TH is widely used in global cerebral hypoxemia, such as post cardiac arrest, showing evidence of good outcomes in controlled prospective study.[3-7] But, in traumatic brain injury (TBI) TH shows conflicting outcomes in several studies.[6,8,9] There are many evidences in historical, pathophysiological, clinical studies, showing TH can be more useful methods in TBI. In this article, we will review TH in treating TBI.

\section{Historical Base}

The historical background of TH was initiated in BC 450. Hippocrates found snow and ice packing reduce hemorrhage in

Received on August 5, 2015 Revised on August 17, 2015

Accepted on August 17, 2015

Correspondence to: Dong-Keun Hyun, Department of Neurosurgery, Inha University Hospital, 27 Inhang-ro, Jung-gu, Incheon 22332, Korea

Tel: +82-32-890-2370, Fax: +82-32-890-2127

E-mail: dkhyun@inha.ac.kr

*No potential conflict of interest relevant to this article was reported. wound. $[10,11]$ Total body cooling method was used for treating tetanus in $4^{\text {th }}-5^{\text {th }}$ century.[12] Russians have applied TH by covering people with snow in an attempt to resuscitate since 1803.[13] Baron de Larrey, Napoleon's chief surgeon during Russian campaign in 1812, packed limbs in ice prior to amputations to reduce pain and bleeding. He found that 
soldiers who were placed near to a fire died faster than those who remained hypothermic state.[12] In 1892, at Johns Hopkins, Sir Wiliam Osler experimented with hypothermia on patients with typhoid fever and reported favor outcomes in mortality from $24.2 \%$ to $7.1 \%$.[12] The earliest recorded clinical use of TH was in 1937 when Dr. Temple Fay cooled a female patient with metastatic breast cancer to $32^{\circ} \mathrm{C}$ for 24 hours, and she relieved metastatic cancer pain. [13-15] Bigelow et al. introduced TH for neurologic protection during cardiac surgery in animals and this remain the current practice.[16,17] At the end of 1950s, TH was used in neurosurgery and for neurological indications became increasingly common.[18] In 1958, clinical trial of TH in the treatment of comatous patients by cardiac arrest showed good outcome compared to normothermia group.[19] However after 1960s, TH was not widely used because of the difficulty in managing side effect. There are complications such as arrhythmia, coagulopathy, and infection in moderate hypothermia.(28-32 $\left.{ }^{\circ} \mathrm{C}\right)[11]$ In 1979-80s, mild hypothermia demonstrate good outcome.[20-24] Thus, in the 1990s, researches on the use of TH with mild degree cooling in animal models were widely implemented.[25-27]

\section{Experiment in TBI}

Clifton et al. first reported that the effectiveness of moderate hypothermia in TBI by rat model experiment.[28] In this study, moderate hypothermia group performed by $30^{\circ} \mathrm{C}$ significantly reduced mortality rates compared to normothermic group. Lyeth et al.[29] and Dietrich et al.[30] also reported that moderate hypothermia showed good outcomes in TBI by animal studies. Dixon et al. reported that posttraumatic hypothermia reduced overall contusion volume following controlled cortical impact injury.[31] The therapeutic window for neuroprotection in the clinical field is one of the potential limitations of therapeutic treatment strategy. Although various pharmacological strategies have shown efficacy when administered before or immediately, few interventions have provided clinically significant protection when given in a delayed post traumatic fashion.[32] Thus, in terms of the treatment window for post traumatic hypothermia, Markgraf et al. reported improved neurological outcome if moderate hypothermia ( 3 hours at $30^{\circ} \mathrm{C}$ ) was started within 60 minutes but not over 90 minutes after TBI. [33] The time period between 60-90 minute window would appear relatively limited in clinical field, it is unclear the therapeutic window in animals be applicated in humans.[32]

Post traumatic hypothermia reduced the axonal damage extension in models of TBI.[34-37] Because diffuse axonal injury (DAI) play an important role in the functional consequence of TBI, these findings show the importance of TH in TBI.

\section{Methodology of TH}

The TH is progressed by 3 phases. The induction phase is the period of maximizing speed of cooling to rapidly bring the temperature to $32-34^{\circ} \mathrm{C}$. Patients should be in intubation state due to sedation and muscle relaxation to prevent shivering to suppress heat protection. The maintenance phase maintained the goal body temperature 12-24 hours. (The optimal duration is unknown) The cooling device water temperature should be checked every hour. The administration of paralytic agent needed to suppress shivering. Rewarming phase is the most important phase, because complications such as hypotension, brain swelling, and electrolyte imbalance could be occur. The goal of rewarming phase is to reach normal body temperature over 12-24 hours. The body temperature can elevate $0.25^{\circ} \mathrm{C}$ or less per hour. If the body temperature was normalized, all sedation should be stop.

Systemic cooling can be obtained by surface cooling, most often with a cooling blanket or cooling with endovascular catheters.[2] Surface cooling methods have benefits; safe and easy to use, good temperature modulation, feedback loop. Nevertheless, the risks of surface cooling methods are slow cooling, slow heat flux, and shivering. Endovascular cooling methods are good at temperature modulation, cooling speed and feedback loop. The choice of cooling device, whether surface or endovascular is depend on the degree of target hypothermic temperature, patient population and the opinion of the physician.

\section{Pathophysiology of TH}

The metabolic rate of brain decreased by $6-7 \% / 1^{\circ} \mathrm{C}$ 
drop of body temperature.[38] In this regard, hypothermic therapy was reported in the 1960 's to decrease $\mathrm{O}_{2}$ consumption and $\mathrm{CO}_{2}$ production as well as other indicators of metabolism.[39,40] Thus, the metabolic and energy demands were thought to be the beneficial effects of hypothermia. However, several investigative studies demonstrated last decade that more modest levels of hypothermia have effectiveness on multiple mechanisms felt to be responsible for secondary brain injury mechanism.[41] Secondary brain injury is initiated at the moment of injury with progression over the ensuing minutes, hours, and days.[2] Secondary injury plays a major role in patient's prognosis and treatment outcome. The pathophysiologic mechanisms about the secondary damage are not totally understood. Overall effects of biomolecular and physiological changes in the brain injury, including neuroinflammatory processes with release of cytokines, excitotoxic substances, cerebral edema, increased intracranial pressure (ICP), and compromised cerebral blood flow with cerebral ischemia and apoptosis, may be involved.[2] Hypothermia affect small variations in the temperature of the brain during or after an ischemic or traumatic injury change hemodynamic events. Moreover, there are excitatory, calcium dependent intercellular signaling, inflammation and edema apoptosis as well as molecular markers of the post-injured brain. In the area of excitatory, early studies showed that extracellular levels of the excitatory amino acid glutamate and other neurotransmitters after brain injury were reduced following mild posttraumatic hypothermia.[42-45] Mild hypothermia also have positive effect on protect against blood brain barrier permeability after increase the permeability of the tight cerebral capillaries due to both ischemic and traumatic injury.[46-48] Increase of permeability cause brain edema, it can be an effect of swelling of brain cells, because of cell membrane damage from hypoxia, and cytotoxic and excitatory substances.[2]

One of the most important effects of hypothermia is the preservation of the blood-brain barrier following the disruptive effects of ischemia-reperfusion, traumatic injury, or even mannitol administration.[38] Moreover hypothermia attenuate the release of NO that increase vascular permeability of brain endothelial cells, which decreases neuronal NO synthase recruitment and suppresses aquaporin 4 expression.[38,49,50]

In a study recently investigated reports that hypothermia has been shown to influence signaling cascades associated with hippocampal-dependent learning and memory and may present a molecular mechanism that hypothermia treatment elicits to improve function outcome after TBI.[51]

Overall, hypothermia exerts a protective effect over a variety of injurious mechanisms occuring in the brain following ischemia-reperfusion or trauma. In early phase, these effects involve a decrease in cerebral metabolism, mitochondrial injury, ion pump dysfunction, and excitotoxicity.[38] In more delayed phase, reperfusion injury, ROS production, inflammation, apoptosis, blood-brain barrier permeability, and edema formation could be attenuated by hypothermia.[38] Hypothermia is also concerned in neuronal cell regeneration and neuronal circuit repair.[50]

Thus, the ability of post brain injury temperature to affect the acute and more delayed biochemical and genetic responses to injury has expanded our understanding of the complexity of the consequences that temperature may have on pathophysiology and recovery after that.[32]

\section{Clinical Studies}

In 1960's many hospitals used profound hypothermia to treat severe TBI.[52] However the treatment results were poor due to serious side effects including infection, thrombosis, and arrhythmia. In the 1970's therapeutic hypothermia to treat TBI was ceased. In 1990's several clinical studies demonstrate that modest level of hypothermia improved outcomes in clinically relevant models of TBI, attention again turned to the use of hypothermia in treatment of TBI.[53-58] Improving patient outcome is also related to prevention of cerebral hypoxia after TBI.[59] Good outcomes of therapeutic hypothermia were achieved by reducing hypoxic events following TBI with the use of brain tissue oxygen-guided cerebral perfusion pressure management and therapeutic mild hypothermia.[60,61] Marion et al. compared the treatment outcomes of hypothermia to normothermia. 82 patients of TBI was enrolled, $62 \%$ of patients underwent hypothermia treatment demonstrated good outcomes compared to $38 \%$ of those in the normothermic group.[56] Jiang et al. also researched the effects of longterm (3-14 days) mild therapeutic hypothermia $\left(33-35^{\circ} \mathrm{C}\right)$ on outcome in 87 patients with severe TBI.[62] They found 
that the rate of complications between the groups (normothermia and hypothermia) was not significantly different. Hypothermia group demonstrates markedly reduced ICP and inhibited hyperglycemia. The duration of $\mathrm{TH}$ is important in both preclinical and clinical TBI investigation. Jiang et al. reported the correlation of hypothermic duration and behavioral outcome after severe TBI.[54] They conclude that patients underwent cooling for five days demonstrated better behavioral outcomes than those patients underwent three days. Tokutomi et al. reported that temperature control of $35-35.5^{\circ} \mathrm{C}$ is sufficient to control intracranial hypertension without inducing cardiac dysfunction.[63] Although it is not clear the mechanisms responsible for the actions of hypothermia in the treatment of TBI, mild degree TH have a reliable association with the expression of commexin-43 and glutamate-transporter- 1 in the hippocampus following TBI in rats. TH also improved brain edema induced by TBI and neurologic deficit. It seems accompanied by decreasing in expression of connexin-43, increased after TBI in normal condition.[64] In accordance with previous studies, a model of fluid percussion injury, post-traumatic hypothermia significantly attenuated cell death within the hippocampus and attenuated caspase-3 upregulation, thereby reducing markers of apoptosis.[65]

Many studies performed to investigate the favorable outcomes by $\mathrm{TH}$ in single center. Polderman summarized recent single center studies and review them.[66] The conculsions were, use of mild hypothermia could be a useful modality in the treatment of neurological injuries and further investigation should be need.

Multicenter randomized control study was initiated by Clifton et al.[8] to evaluate the efficacy of modest hypothermia in a large number of severe TBI patients. The study named NAVIS-H (North American Brain Injury Study; Hypothermia), 392 adult patients with severe TBI were randomized into hypothermia and normothermia groups from 1994 to 1998 . 193 patients enrolled normothermia group and 199 patients enrolled hypothermia group. However in contrast to several single center studies, $[53,56]$ there were no beneficial outcome in hypothermic group and mortality rate was not different. However in patients younger than 45 years old, percentage with poor outcome was diminished in hypothermia group (52\%) than normothermia group (76\%). Moreover patients with body temperature lower than $35^{\circ} \mathrm{C}$ on admission showed more favorable outcomes with hypothermia therapy.

Clifton et al. reported NAVIS-H2 sutdy : Very early hypothermia induction in patients with severe brain injury.[67] NAVIS-H2 study was designed by based on the result of NAVIS-H1. Multicenter randomized study was performed only to young age group (16-45 years old). Very early induction was initiated within 2.5 hours admission, compared to normothermia group. The overall primary analysis was not significantly different between hypothermia group and normothermia group. But in subgroup analysis hypothermia group demonstrated favorable outcome after surgical hematoma removal than normothermia group. The percentage of poor outcome in hypothermia group was 33\% versus normothermia group $69 \%$.

Another multicenter randomize controlled trial initiated in 2011 by Andrew et al.[68] Eurotherm 3235 trial will be complete in 2016, as of now (20 Mar 2013) over 1,256 patients have been screened and 210 patients have been randomized. After the end of this trial TH will be essential to confidently confirm or refute outcome benefit, rather than merely palliation.

Suehiro et al. reported multicenter randomize trial with Japan neurotrauma databank.[69] Total 401 patients were classified in 3 groups; 225 patients for no temperature management, 129 patients for intensive normothermia, and 47 patients for hypothermia. No temperature management group did not receive brain temperature management, but there is routine medical management including ice packs or drugs to control high fever. Brain temperature was maintained strictly below $38^{\circ} \mathrm{C}$ with cooling blankets in patients with normothermia. Patients in the hypothermia group received temperature treatment with maintained below $35^{\circ} \mathrm{C}$. The results of favorable outcome rate of hypothermia $(52.4 \%)$, normothermia $(26.9 \%)$, and no temperature management $(20.7 \%)$ with evacuated mass lesions in contrast to diffuse injury. There was no significant favor outcome in diffuse brain injury patients among 3 groups. They conclude that, patient outcomes with diffuse injury were not improved by hypothermia induction. But hypothermia therapy was significant in protecting the brain of patients with evacuated mass lesions.

Recently many researches are performed about TH. In particular it is possible to expect more results from the mul- 
ticenter randomized studies. It is clear that $\mathrm{TH}$ had good effect and side effect, we need the protocol which had minimal side effect and maximal therapeutic effect. In the protocol, the optimal cooling time and temperature should be contained, as well as rewarming phase. Moreover cooling devices and pharmacologic agents should be evaluated for best therapeutic result. More researches will supplement the sum mentioned earlier, the patients in TBI will be treated with the TH actively.

\section{References}

1) Bernard SA, Buist M: Induced hypothermia in critical care medicine : a review. Crit Care Med 2003; 31: 2041-51.

2) Sandestig A, Romner B, Grande PO: Therapeutic hypothermia in children and adults with severe traumatic brain injury. Ther Hypothermia Temp Manag 2014; 4: 10-20.

3) Bernard SA, Gray TW, Buist MD, Jones BM, Silvester W, Gutteridge G, et al: Treatment of comatose survivors of out-of-hospital cardiac arrest with induced hypothermia. N Engl J Med 2002; 346: 557-63.

4) Gluckman PD, Wyatt JS, Azzopardi D, Ballard R, Edwards AD, Ferriero DM, et al: Selective head cooling with mild systemic hypothermia after neonatal encephalopathy: multicentre randomised trial. Lancet 2005; 365: 663-70.

5) Hypothermia after Cardiac Arrest Study Group: Mild therapeutic hypothermia to improve the neurologic outcome after cardiac arrest. N Engl J Med 2002; 346: 549-56.

6) Mourvillier B, Tubach F, van de Beek D, Garot D, Pichon N, Georges H, et al: Induced hypothermia in severe bacterial meningitis: a randomized clinical trial. JAMA 2013; 310: 2174-83.

7) Shankaran S, Laptook AR, Ehrenkranz RA, Tyson JE, McDonald SA, Donovan EF, et al: Whole-body hypothermia for neonates with hypoxic-ischemic encephalopathy. N Engl J Med 2005; 353: 1574-84.

8) Clifton GL, Miller ER, Choi SC, Levin HS, McCauley S, Smith KR Jr, et al: Lack of effect of induction of hypothermia after acute brain injury. N Engl J Med 2001;
344: 556-63.

9) Mclyntyre LA, Fergussun DA, Hébert PC, Moher D, Hutchison JS: Prolonged therapeutic hypothermia after traumatic brain injury in adults: a systematic review. JAMA 2003; 289: 2992-9.

10) Karnatovskaia LV, Wartenberg KE, Freeman WD: Therapeutic hypothermia for neuroprotection: history, mechanisms, risks, and clinical applications. Neurohospitalist 2014; 4: 153-63.

11) Polderman KH: Application of therapeumic hypothermia in the ICU: opportunities and pitfalls of a promising treatment modality. Part 1: Indications and evidence. Intensive Care Med 2004; 30: 556-75.

12) Wang H, Olivero W, Wang D, Lanzino G: Cold as a therapeutic agent. Acta Neurochir (Wien) 2006; 148: 565-70; discussion 569-70.

13) Alzaga AG, Salazar GA, Varon J: Resuscitation great. Breaking the thermal barrier: Dr. Temple Fay. Resuscitation 2006; 69: 359-64.

14) Fay T: Observations on prolonged human refrigeration. NY State J Med 1940; 40: 1351-4.

15) Fay T: Observations on generalized refrigeration in cases of severe cerebral trauma. Assoc Res Nerv Ment Dis Proc 1945; 24: 611-9.

16) Bigelow WG, Mcbirnie JE: Further experiences with hypothermia for intracardiac surgery in monkeys and groundhogs. Ann Surg 1953; 137: 361-5.

17) Cook D: Changing temperature management for cardiopulmonary bypass. Anesth Analg 1999; 88: 1254-71.

18) Lazorthes G, Campan L: Hypothermia in the treatment of craniocerebral traumatism. J Neurosurg 1958; 15: 162-7.

19) Williams Gr Jr, Spencer FC: The clinical use of hypothermia following cardiac arrest. Ann Surg 1958; 148: 462-8.

20) Busto R, Dietrich WD, Globus MY, Valdés I, Scheinberg P, Ginsberg MD: Small differences in intraischemic brain temperature critically determine the extent of ischemic neuronal injury. J Cereb Blood Flow Metab 1987; 7: 729-38.

21) Gilston A: Another chance for therapeutic hypothermia? Crit Care Med 1985; 13: 775.

22) Norwood WI, Norwood CR, Castaneda AR: Cerebral anoxia: effect of deep hypothermia and $\mathrm{pH}$. Surgery 
1979; 86: 203-9.

23) Safar P: Resuscitation from clinical death: pathophysiologic limits and therapeutic potentials. Crit Care Med 1988; 16: 923-41.

24) Symington GR, Mackay IR, Currie TT: Improvement in multiple sclerosis during prolonged induced hypothermia. Neurology 1977; 27: 302-3.

25) Irazuzta JE, Pretzlaff R, Rowin M, Milam K, Zemlan FP, Zingarelli B: Hypothermia as an adjunctive treatment for severe bacterial meningitis. Brain Res 2000; 881: 88-97.

26) Leonov Y, Sterz F, Safar P, Radovsky A, Oku K, Tisherman $S$, et al: Mild cerebral hypothermia during and after cardiac arrest improves neurologic outcome in dogs. J Cereb Blood Flow Metab 1990; 10: 57-70.

27) Ridenour TR, Warner DS, Todd MM, McAllister AC: Mild hypothermia reduces infarct size resulting from temporary but not permanent focal ischemia in rats. Stroke 1992; 23: 733-8.

28) Clifton GL, Jiang JY, Lyeth BG, Jenkins LW, Hamm RJ, Hayes RL: Marked protection by moderate hypothermia after experimental traumatic brain injury. $\mathrm{J}$ Cereb Blood Flow Metab 1991; 11: 114-21.

29) Lyeth BG, Jiang JY, Liu S: Behavioral protection by moderate hypothermia initiated after experimental traumatic brain injury. J Neurotrauma 1993; 10: 57-64.

30) Dietrich WD, Alonso O, Busto R, Globus MY, Ginsberg MD: Post-traumatic brain hypothermia reduces histopathological damage following concussive brain injury in the rat. Acta Neuropathol 1994; 87: 250-8.

31) Dixon CE, Markgraf CG, Angileri F, Pike BR, Wolfson B, Newcomb JK, et al: Protective effects on moderate hypothermia on behavioral deficits but not necrotic cavitation following cortical impact injury in the rat. $\mathrm{J}$ Neurotrauma 1998; 15: 95-103.

32) Dietrich WD, Bramlett HM: The evidence for hypothermia as a neuroprotectant in traumatic brain injury. Neurotherapeutics 2010; 7: 43-50.

33) Markgraf CG, Clifton GL, Moody MR: Treatment window for hypothermia in brain injury. J Neurosurg 2001; 95: 979-83.

34) Koizumi H, Povlishock JT: Posttraumatic hypothermia in the treatment of axonal damage in an animal model of traumatic axonal injury. J Neurosurg 1998; 89: 303-9.
35) Marion DW, White MJ: Treatment of experimental brain injury with moderate hypothermia and 21-aminosteroids. J Neurotrauma 1996; 13: 139-47.

36) Maxwell WL, Donnelly S, Sun X, Fenton T, Puri N, Graham DI: Axonal cytoskeletal responses to nondisruptive axonal injury and the short-term effects of posttraumatic hypothermia. J Neurotrauma 1999; 16: 122534.

37) Taft WC, Yang K, Dixon CE, Clifton GL, Hayes RL: Hypothermia attenuates the loss of hippocampal microtubule-associated protein 2 (MAP2) following traumatic brain injury. J Cereb Blood Flow Metab 1993; 13: 796-802.

38) Polderman KH: Mechanisms of action, physiological effect, and complications of hypothermia. Crit Care Med 2009; 37(7 Suppl): S186-202.

39) Rosomoff HL: The effects of hypothermia on the physiology of the nervous system. Surgery 1956; 40: 328-36.

40) Rosomoff HL, Hikaday DA: Cerebral blood flow and cerebral oxygen consumption during hypothermia. Am J Physiol 1954; 179: 85-8.

41) Dietrich WD: The importance of brain temperature in cerebral injury. J Neurotrauma 1992; 9 Suppl 2: S47585.

42) Globus MY, Alonso O, Dietrich WD, Busto R, Ginsberg MD: Glutamate release and free radical production following brain injury: effects of posttraumatic hypothermia. J Neurochem 1995; 65: 1704-11.

43) Jiang JY, Liang YM, Luo QZ, Zhu C: Effect of mild hypothermia on brain dialysate lactate after fluid percussion brain injury in rodents. Neurosurgery 2004; 54 : 713-7; discussion 717-8.

44) Koizumi H, Fujisawa H, Ito $H$, Ito $H$, Maekawa T, Di $\mathrm{X}$, Bullock R: Effects of mild hypothermia on cerebral blood flow-independent changes in cortical extracellular levels of amino acids following contusion trauma in the rat. Brain Res 1997; 747: 304-12.

45) Lyeth BG, Jiang JY, Robinson SE, Guo H, Jenkins LW: Hypothermia blunts acetylcholine increase in CSF of traumatically brain injured rats. Mol Chem Neuropathol 1993; 18: 247-56.

46) Arican N, Kaya M, Yorulmaz C, Kalayci R, Ince H, Kucuk M, et al: Effect of hypothermia on blood-brain barrier permeability following traumatic brain injury in 
chronically ethanol-treated rats. Int J Neurosci 2006; 116: 1249-61.

47) Jiang JY, Lyerh BG, Kapasi MZ, Jenkins LW, Povlishock JT: Moderate hypothermia reduces blood-brain barrier disruption following traumatic brain injury in the rat. Acta Neuropathol 1992; 84: 495-500.

48) Kinoshita K, Chatzipanteli K, Alonso OF, Howard M, Dietrich WD: The effect of brain temperature on hemoglobin extravasation after traumatic brain injury. $\mathrm{J}$ Neurosurg 2002; 97: 945-53.

49) Mueller-Burke D, Koehler RC, Martin LJ: Rapid NMDA receptor phosphorylation and oxidative stress precede striatal neurodegeneration after hypoxic ischemia in newborn piglets and are attenuated with hypothermia. Int J Dev Neurosci 2008; 26:67-76.

50) Yenari MA, Han HS: Neuroprotective mechanisms of hypothermia in brain ischaemia. Nat Rev Neurosci 2012; 13: 267-78.

51) Atkins CM, Oliva AA Jr, Alonso OF, Chen S, Bramlett $\mathrm{HM}, \mathrm{Hu} \mathrm{BR}$, et al: Hypothermia treatment potentiates ERK1/2 activation after traumatic brain injury. Eur $\mathrm{J}$ Neurosci 2007; 26: 810-9.

52) Sedezimir CB: Therapeutic hypothermia in cases of head injury. J Neurosurg 1959; 16: 407-14.

53) Clifton GL, Allen S, Barrodale P, Plenger P, Berry J, Koch S, et al: A phase II study of moderate hypothermia in severe brain injury. J Neurotrauma 1993; 10: 263-71; discussion 273.

54) Jiang JY, Xu W, Li WP, Gao GY, Bao YH, Liang YM, et al: Effect of long-term mild hypothermia or shortterm mild hypothermia on outcome of patients with severe head injury. J Cereb Blood Flow Metab 2006; 26: 771-6.

55) Marion DW, Obrist WD, Carlier PM, Penrod LE, Darby JM: The use of moderate therapeutic hypothermia for patients with severe head injuries: a preliminary report. J Neurosurg 1993; 79: 354-62.

56) Marion DW, Penrod LE, Kelsey SF, Obrist WD, Kochanek PM, Palmer AM, et al: Treatment of traumatic brain injury with moderate hypothermia. N Engl J Med 1997; 336: 540-6.

57) Metz C, Holzschuh M, Bein T, Woertgen C, Frey A, Frey I, et al: Moderate hypothermia in patients with severe head injury: cerebral and extracerebral effects. J
Neurosurg 1996; 85: 533-41.

58) Tateishi A, Soejima Y, Taira Y, Nakashima K, Fujisawa $\mathrm{H}$, Tsuchida E, et al: Feasibility of the titration method of mild hypothermia in severely head-injured patients with intracranial hypertension. Neurosugery 1998; 42: 1065-9; discussion 1069-70.

59) Chesnut RM, Marshall LF, Klauber MR, Blunt BA, Baldwin N, Eisenberg HM, et al: The role of secondary brain injury in determining outcome from severe head injury. J Trauma 1993; 34: 216-22.

60) Liu WG, Qiu WS, Zhang Y, Wang WM, Lu F, Yang XF: Effects of selective brain cooling in patients with severe traumatic brain injury: a preliminary study. J Int Med Res 2006; 34: 58-64.

61) Patterson J, Bloom SA, Coyle B, Mouradjian D, Wilensky EM: Successful outcome in severe traumatic brain injury: a case study. J Neurosci Nurs 2005; 37: 236-42.

62) Jiang J, Yu M, Zhu C: Effect of long-term mild hypothermia therapy in patients with severe traumatic brain injury: 1-year follow-up review of 87 cases. J Neurosurg 2000; 93: 546-9.

63) Tokutomi T, Morimoto K, Miyagi T, Yamagichi S, Ishikawa K, Shigemori M: Optimal temperature for the management of severe traumatic brain injury: effect of hypothermia on intracranial pressure, systemic and intracranial hemodynamics, and metabolism. Neurosurgery 2007; 61(1 Suppl): 256-65; discussion 265-6.

64) Li YH, Zhang CL, Zhang XY, Zhou HX, Meng LL: Effect of mild induced hypothermia on hippocampal connexin 43 and glutamate transporter 1 expression following traumatic brain injury in rats. Mol Med Rep 2015; 11: 1991-6.

65) Maier CM, Ahern Kv, Cheng ML, Lee JE, Yenari MA, Steinberg GK: Optimal depth and duration of mild hypothermia in a focal model of transient cerebral ischemia: effects on neurologic outcome, infarct size, apoptosis, and inflammation. Stroke 1998; 29: 2171-80.

66) Polderman KH: Induced hypothermia and fever control for prevention and treatment of neurological injuries. Lancet 2008; 371: 1955-69.

67) Clifton GL, Valadka A, Zygun D, Coffey CS, Drever P, Fourwinds S, et al: Very early hypothermia induction in patients with severe brain injury (the National Acute Brain Injury Study: Hypothermia II): a randomised 
trial. Lancet Neurol 2011; 10: 131-9.

68) Andrews PJ, Sinclair LH, Harris B, Baldwin MJ, Battison CG, Rhodes JK, et al: Study of therapeutic hypothermia $\left(32\right.$ to $35^{\circ} \mathrm{C}$ ) for intracranial pressure reduction after traumatic brain injury (the Eurotherm3235trial): outcome of the pilot phase of the trial. Trials 2013; 14:
277.

69) Suehiro E, Koizumi H, Kunitsugu I, Fujisawa H, Suzuki M: Survey of brain temperature management in patients with traumatic brain injury in the Japan neurotrauma data bank. J Neurotrauma 2014; 31: 315-20. 